\begin{abstract}
HHS Public Access
Author manuscript

Appl Econ. Author manuscript; available in PMC 2018 October 19.

Published in final edited form as:

Appl Econ. 2018 ; 50(58): 6327-6340. doi:10.1080/00036846.2018.1489519.

\section{Estimating the monetary benefits of medicare eligibility for reducing the symptoms of dementia}

\author{
Robert J. Brent \\ Department of Economics, Fordham University, New York, NY, USA
}

Abstract

We adopt a three-component method based on the idea of cost-saving for estimating the monetary benefits of Medicare eligibility for reducing dementia symptoms. The method involves Medicare eligibility lowering dementia symptoms, which reduces the need for dependent living, which in turn lowers caregiving costs. We use the Regression Discontinuity approach to establish a causal link between Medicare eligibility and dementia. The novel aspect of the study comes from using a quality-of-life proxy measure for the utility function to derive the marginal rate of substitution between dementia symptoms reduction and dependent living arrangements.
\end{abstract}

\title{
Keywords
}

Dementia; medicare; benefits

\section{Keywords}

D61 Cost-Benefit Analysis; J14 Economics of the Elderly; I12 Health Production

\section{Introduction}

Dementia is a term used to describe various symptoms of cognitive decline, involving memory, language and thinking that are severe enough to affect daily activities. It is caused by progressive brain cell death that happens over a course of time and by other factors such as a head injury, a stroke or a brain tumour. In 2015, worldwide, there were 897 million people aged 60 and over and $5.2 \%$ of these had dementia; and in North America, there were 147 million people over the age of 60 , and $6.4 \%$ of these had dementia. Global costs of dementia were US $\$ 818$ billion in 2015 , up by $34 \%$ from 2010 , in terms of mortality, loss of quality of life (QoL) and the need for informal and formal caregiving services (World Alzheimer Report 2015).

This is an Open Access article distributed under the terms of the Creative Commons Attribution-NonCommercial-NoDerivatives License (http://creativecommons.org/licenses/by-nc-nd/4.0/), which permits non-commercial re-use, distribution, and reproduction in any medium, provided the original work is properly cited, and is not altered, transformed, or built upon in any way.

CONTACT Robert J. Brent Brent@fordham.edu.

Disclosure statement

No potential conflict of interest was reported by the author. 
Given the prevalence and costs of this disease, and because of the worldwide ageing of the population making it likely that the prevalence of dementia will increase exponentially over time, it is important that interventions for dementia be identified and evaluated using costbenefit analysis (CBA) to assess whether they are socially worthwhile. At this time, there is no cure for dementia, in which case the main options are to delay its onset or mitigate the symptoms. Early detection is key in this process as it can allow pharmacological treatments and caregiver interventions to take place that slow down the entry into costly nursing homes. Using a quality-adjusted value of a statistical life to measure benefits, and comparing this with drug costs, caregiver costs and nursing home costs, Weimer and Sager (2009) found that the mean net-benefits of early detection with drug treatment and caregiver support was $\$ 94,000$ over the lifetime of those affected by Alzheimer's disease (AD), the main form of dementia. ${ }^{1}$ In this CBA, the effectiveness of early prevention was assumed rather than estimated directly using data.

There are CBAs that can show cost savings accruing when caregiving support and drug treatment are altered by a dementia intervention, such as the New York Caregiver Support Intervention (Long, Moriarty, and Mittelman et al. 2014). But, very few CBAs exist that can show that an intervention actually lowers dementia symptoms and is therefore worthwhile as treatment, as opposed to just prevention by early detection or by adding caregiver support. This is not surprising given that there is no current cure at this time in terms of affecting brain pathology. However, treatment is still a possibility if dementia symptoms can be observed to be lowered by some intervention. An example is the CBA carried out on years of education by Brent (2017) - hereafter referred to as 'the education dementia CBA'. The education dementia CBA estimated how the symptoms of dementia were reduced for each year of schooling that a person had experienced and valued this reduction by the dependent living cost savings that were generated.

The education dementia CBA was an exception because it was built on an extensive literature that reported that education was one of the few causal ways that dementia has been shown to be reduced (World Alzheimer Report 2014). The challenge is to identify and quantify the benefits of other interventions that can be shown to have a causal impact on dementia symptoms. In this regard, a recent set of studies by Card, Dobkin, and Maestas $(2008,2009)$ is important as it used a Regression Discontinuity (RD) approach to estimate the causal impact of Medicare for improving healthcare outcomes. This research revealed that accessing Medicare health insurance both increased healthcare utilization and saved lives via more visits to emergency departments for non-deferrable conditions. The 7-day mortality reduction was about $0.8-1.0$ percentage points. They conjecture that Medicare might affect other dimensions of health than emergency visits and that these effects may persist over a longer period of time than the 9 months that they observed. This opens up the question whether something as widespread as dementia might also be something that Medicare eligibility can mitigate.

\footnotetext{
${ }^{1}$ In this study, we do not distinguish between Alzheimer's dementia and other forms of dementia (such as Vascular and Lewy body dementia) because, although our data comes from Alzheimer's Disease Centers, our dependent variable in this data set is based on a generic dementia score. Note that Zhu, Scarmeas, and Stavitsky et al. (2008) did not find a statistically significant difference in the cost of care for AD patients and those with Lewy body dementia and the cost of care is what we are analysing in this study.
} 
Using the RD for Medicare eligibility is very straightforward, as one does not have to determine the best time interval to use for the design. The cut-off is precise; it is a 'hard' cutoff level. One first becomes eligible for Medicare at 65 years of age. We use a varying slopes RD version, which shows how dementia is affected by age before and after the 65 years cutoff for Medicare eligibility. The downward difference (discontinuity) between the slopes the year before and the year after at the 65 year cut-off records any causal shift that Medicare eligibility has on dementia symptoms. ${ }^{2}$ The Card et al. studies used a few days before and after 65 years as their cut-off. This made sense for their intervention, which was access to an emergency room that could immediately save a person's life. On the other hand, using a few days makes little sense for our intervention which is reducing dementia symptoms by having greater access to medical services. Allowing a year from turning 65 years makes more sense as this gives sufficient time for dementia changes to occur and be monitored.

We then see if there are any monetary benefits that are forthcoming from reducing dementia symptoms in this way. To do this monetarization part, we will use, and adapt, the three component cost-savings benefits method that was first used for the education dementia CBA. 3 The adaption involves using a QoL measure to estimate the extent to which any dementia symptoms reduction leads to changes in dependent living which generates the cost savings. We will directly estimate the effectiveness of Medicare eligibility for reducing dementia symptoms, and the consequential changes in dependent living arrangements, using a national data set on dementia. The main findings are that Medicare eligibility does causally reduce dementia symptoms and that this reduction can be valued at around $\$ 9337$ per person at the year of eligibility and at $\$ 1350$ per person 7 years after the age of 65 years.

The main value added of this article is that it builds upon the education dementia paper by including education and the associated controls that established causality for this variable as independent variables to allow for Medicare eligibility to be fully tested. Education has a strong impact on dementia symptoms and it is important to detect the impact of Medicare eligibility on dementia symptoms reduction separate from education and any hereditary factors that influence dementia. A second important contribution is that we take the threestep method for estimating cost-savings used in the education dementia CBA and adapt it in order to allow for the preferences of those with dementia to impact the evaluation of the benefits of Medicare eligibility. We do this by estimating the utility function of those with dementia as proxied by a QoL measure. The end result is that we (a) provide a comprehensive test of whether Medicare eligibility has a causal impact on dementia symptoms reduction; (b) generate an estimate of the monetary benefits that the dementia symptoms reduction from Medicare eligibility achieves; (c) supply some understanding of how these monetary benefits from Medicare eligibility might take place; and (d) carry out a preliminary CBA of Medicare as a dementia intervention.

\footnotetext{
${ }^{2}$ Note that dementia is monotonically increasing with age. It does not change sign; it does not rise and fall in the absence of Medicare eligibility. So a quadratic of cubic RD design is not plausible. These other designs were tested and, not surprisingly, they were not improvements.

${ }^{3}$ For a detailed analysis of the role of cost-savings as a method to value the benefits in CBA, see Brent $(2006,2014)$.
} 
The remainder of the article is structured as follows. Section II gives the background to the analysis, in terms of the data source and the measures of dementia symptoms and QoL that we will be using. The background to Medicare eligibility and health insurance is provided in the two Card et al. papers cited earlier. We draw upon some of this material in our closing section. Section III presents the method for estimating the benefits of Medicare eligibility that is the unifying construct for this study. The estimation framework is in Section IV and this is followed by the data summary (Section V) and the results (Section VI). Section VII gives the summary and conclusions.

\section{Background}

\section{The data source}

The data we will be using to estimate the benefits of Medicare eligibility for reducing dementia symptoms comes from the National Alzheimer's Coordinating Center (NACC). NACC has constructed a data set on dementia, called the Uniform Data Set (UDS), which has been fully operational since 2005. These data consist of demographic, clinical, diagnostic and neuropsychological information on participants with normal cognition, mild cognitive impairment and dementia at 32 US Alzheimer's Disease Centers (ADCs). Steps were undertaken to standardize the data across ADCs. The data were collected by trained clinicians using structured interviews and objective test measures. This data set is fully explained elsewhere (Morris, Weintraub, and Chui 2006; Beekly, Ramos, and Lee et al. 2007; Weintraub, Salmon, and Mercaldo et al. 2009). This data set has been used by a number of researchers to analyse the progression of dementia, such as by Besser, Gill, and Monsell et al. (2014) for body mass index and weight change, and by Burke, Maramaldi, and Cadet et al. (2016) for depression, sleep disturbance and apolipoprotein E (APOE).

Although the UDS is the largest of its kind in the US, it covers over 33,000 participants and includes many administrative, demographic and behavioural variables as of September 2015, it is nonetheless not nationally representative, seeing that participants voluntarily present at one of the ADCs for an examination and they have to provide informed consent. Some were referred by a relative or friend, some by a clinician, some by ADC solicitation and the others by non-ADC media appeals or unknown sources. This study uses the initial visit data for 17,239 participants collected between September 2005 and May 2015. This data set was also used for the education dementia CBA

\section{The measure of dementia}

Brain pathology (such as amyloid plaques on the outside of the neurons or fibres on the inside of brain cells for $\mathrm{AD}$, or lesions for vascular dementia) likely occurs many years before the onset of clinical dementia. This means that brain pathology is not a sufficient condition for a diagnosis of dementia. It may also not be a necessary condition as one can have cognitive impairment without the brain pathology. For this reason, it is important to employ a measure of dementia that focuses on cognitive functioning rather than pathology. The instrument that we will be using to measure dementia is the Clinical Dementia Rating (CDR) scale. The CDR is a well-accepted measure of dementia severity used globally, based primarily on a neurological exam and informant reporting and this was administered to each 
NACC participant at each visit by a clinician. There are six domains in the CDR: memory, orientation, judgement and problem solving, community affairs, home and hobbies, and personal care. Each domain is assessed using a 0-3 interval. The CDR-SB (the CDR sum of boxes) is the aggregate score across all six domains and this has a range of $0-18$. This measure was also used in the education dementia CBA.

\section{The measure of QoL}

The QoL measure that is in the NACC data set that we will be using as a negative proxy for utility is the Geriatric Depression Scale (GDS), short form. This measure has 15 ingredients and we take the sum of the ingredients. Any QoL measure for older adults with dementia faces numerous challenges (see Logson, Gibbons. and McCurry et al. 2002). People with dementia have varying deficits of memory, attention, judgement, insight and communication that could limit the ability to respond to questions about own subjective states. Depression, agitation or psychosis may affect QoL ratings; and what determines QoL at the early stages of dementia (such as the preservation of intellectual capacity) may be different from the determinants at later stages (such as safety and comfort).

Nonetheless, because it is essential that one learn which interventions make the greatest difference to a person's life, some QoL measure is required. Using caregivers' ratings as substitute judgements for patient preferences does not usually work because these proxy preferences differ from those of the patients and there are gender differences in the proxy ratings. So surrogate preferences are not often reliable (Schiffczyk, Jonas, and Lahmeyer et al. 2011), especially as the caregivers tend to project their QoL onto their ratings of patient QoL (Arons, Krabbe, and Scholzel-Dorenbos et al. 2013). In our data set, we were able to avoid the caregiver proxy problem because there is a clinician interviewing the patient who decides whether the person is, or is not, able to complete the GDS rating. Irrespective of the severity of dementia, it was found that around $95 \%$ (of the $97 \%$ of the persons whose competence was assessed by the clinicians) were capable of completing the GDS in our data set. $^{4}$

Although the GDS was originally conceived to be a measure of psychological status, it has become accepted to be a valid measure of QoL among the elderly with and without cognitive impairment. For example, Vagetti, Barbosa Filho, and Moreira et al. (2014), when reviewing the literature concerning whether physical activity improves the QoL of the elderly, use the GDS as one of the 'measurement instruments most commonly used' to record the QoL. That the GDS is an appropriate measure of QoL can be seen directly from two of its constituent ingredients which ask whether patients are basically 'satisfied with their life' (GDS1) and whether they 'feel happy most of the time' (GDS7). Often these happiness and satisfaction measures are the sole ingredient of a QoL index (Graham 2010).

\footnotetext{
${ }^{4}$ There were 17,341 in the sample. Of these, 16,825 were assessed by the clinicians and 15,957 found capable of completing the GDS instrument.
} 


\section{The method for estimating the benefits of medicare}

We will be basically using the three-step method for valuing the cost-saving Medicare benefits from reducing dementia that was used in the education dementia CBA to valuing the dementia benefits of years of education. An intervention first reduces measured dementia symptoms; the dementia symptoms reduction then increases a person's capacity for independent living, which in turn lowers the costs of caregiving. Let $M$ stand for being eligible for Medicare, $D$ for measured dementia symptoms, $L i$ the type of independent living and $C$ the caregiving costs. The three-step method involves applying the chain rule:

$$
\frac{\partial C}{\partial M}=\sum_{i} \frac{\partial C}{\partial L i} \frac{\partial L i}{\partial D} \frac{\partial D}{\partial M}
$$

where $\frac{\partial C}{\partial M}$ is the cost savings benefits from being eligible for Medicare, $\frac{\partial C}{\partial L i}$ is the cost change per change in independent living, $\frac{\partial L i}{\partial D}$ is the change in independent living per unit change in dementia symptoms and $\frac{\partial D}{\partial M}$ is the change in dementia symptoms from being eligible for Medicare.

In the analysis that is to follow, there will be four levels of living independence $\operatorname{Li}(i=1,2,3$, 4). $L 1$ is when the person is living independently and does not need any caregiving and therefore care-giving costs are zero. There are three levels of non-independent living. $L 2$ is where the person needs some assistance and $L 3$ is where the person needs a lot of assistance. Persons in $L 4$ are completely dependent on caregivers. When Medicare reduces dementia symptoms, it results in people transitioning from levels $L 2, L 3$ and $L 4$ to $L 1$ and thereby saving the caregiving costs associated with non-independent living. The cost savings for $L 4$ persons is the greatest and the cost-savings is the least for $L 2$ persons.

With costs $C=C(L i)$, we have three dependent living cost changes to consider:

$$
\frac{\partial C}{\partial L i}=\frac{\partial C}{\partial L 2}, \frac{\partial C}{\partial L 3}, \frac{\partial C}{\partial L 4}
$$

The cost savings from reducing dementia symptoms from each of the three dependent living levels are then given by $(i=2,3,4)$ :

$$
\frac{\partial C}{\partial D}=\sum_{i} \frac{\partial C}{\partial L i} \frac{\partial L i}{\partial D}
$$

To determine the cost savings from reducing dementia symptoms, in addition to knowing the unit cost declines for each of the independent living levels as set out by Eq. (2), we need to know the extent to which reducing dementia symptoms impacts the independent living levels 
$\partial L i l \partial D$. In the education study, this effect was estimated from a production function directly linking $D$ to the $L i$. We will follow this approach in the sensitivity analysis.

But, as an alternative to using the production function, and as part of the main method in this article, we now propose using the utility function relating $D$ to the $L i$. The utility function can be represented by $U=U(L i, D)$, from which we get, using the implicit function theorem:

$$
\frac{\partial L i}{\partial D}=(-) \frac{\partial U}{\partial D} / \frac{\partial U}{\partial L i}
$$

Thus, the effect of $D$ on the $L i$ will be obtained as the marginal rate of substitution (MRS) between $D$ and the $L i$ in the utility function.

To summarize: the cost-saving benefits of Medicare reducing dementia symptoms will be obtained as the product of three components as set out by Eq. (1). The first two components constitute the cost savings from reducing dementia symptoms as defined by Eq. (3), which depend on Eq. (2) and Eq. (4). The final component is to be determined by the effectiveness of Medicare eligibility in reducing dementia symptoms.

\section{Estimation framework}

We will use data to estimate the second and third components of the benefits method and rely on estimates in the literature for the first component involving the living costs laid out in Eq. (2). For the second component involving the MRS in Eq. (4), we need a specification of the utility function $U=U(L i, D)$. We take a linear approximation as our regression equation of the form ${ }^{5}$ :

$$
U=\alpha_{0}+\alpha_{D} D+\alpha_{2} L 2+\alpha_{3} L 3+\alpha_{4} L 4+\alpha_{Z} Z+\varepsilon
$$

where the $a$ are fixed coefficients and $\varepsilon$ is the random error term. $L i$ is a categorical variable and this is represented by the three dummy variables $L 2, L 3$ and $L 4$. Independent living $L 1$ is excluded from the regression and is the reference category. $L 1$ is the reference category because people are transitioning to this level of independent living from the other three types of non-independent living.

Apart from the dementia variable $D$ and the independent living variables $L i$, we include a vector of $Z$ variables as controls. These mainly comprise the set of variables that the literature have found significant in explaining the extent of dementia, including lifestyle, demographic and hereditary variables. Note that, in the regression equation, Medicare $M$ is also one of the controls. Its role is, as with all the other controls, just included to ensure that the coefficients on $D$ and the three $L$ levels are estimated efficiently. From Eq. (5), we derive the second component:

\footnotetext{
${ }^{5}$ When a logarithm specification for $D$ was used, it was found to be statistically insignificant.
} 


$$
\begin{aligned}
\frac{\partial L 2}{\partial D} & =\alpha_{D}\left|\alpha_{2} ; \frac{\partial L 3}{\partial D}=\alpha_{D}\right| \alpha_{3} ; \text { and } \frac{\partial L 4}{\partial D} \\
& =\alpha_{D} / \alpha_{4}
\end{aligned}
$$

The third component involves estimating the effectiveness of Medicare in reducing dementia symptoms. To explain $D$ for the purposes of this article, the role of Medicare is pivotal. Unlike Eq. (5), which is simply a descriptive representative of the utility function, to estimate the effect of $M$ on $D$ we need to use a causal model and employ an identification strategy.

As we explain below, our identification strategy will involve using the RD approach. To implement the RD: we set the treatment variable to be $M=1$ whenever the person is aged 65 or over, we use (Age - 65) as the assignment variable and include the interaction (Age-65) $\times M$ to allow for the slope of the assignment variable to vary before and after the age of 65 years. The $\mathrm{RD}$ equation with the non-Medicare $\mathrm{Z}$ controls added is

$$
\begin{aligned}
D= & \beta_{0}+\beta_{1} M+\beta_{2}(\text { Age }-65) \\
& +\beta_{3}(\text { Age }-65) \times M+\beta_{Z} Z+v
\end{aligned}
$$

where the $\beta$ s are fixed coefficients and $v$ is now the random error term. In this model, the slope of the assignment variable for clients to the left of the cut-off of 65 (where $M=0$ ) is $\beta_{2}$ and the slope for clients to the right of the threshold (for which $M=1$ ) is $\beta_{2}+\beta_{3}$.

From estimating this equation, we obtain the third component:

$$
\frac{\partial D}{\partial M}=\beta_{1}+\beta_{3}(\text { Age }-65)
$$

If Medicare eligibility is to decrease dementia, we would expect that in Eq. (8) we have $\beta_{1}<$ 0 . The role of the interaction term is to allow for the possibility that the impact of Medicare on dementia would likely decline as the client gets older, as the prevalence of dementia generally increases the older a person gets past 65 years, and there is only a fixed amount that receiving Medicare can do to reduce dementia. The expectation then is that $\beta_{3}>0$. This means that the more a client exceeds the Medicare eligibility age, the more there will be an offset to the main, negative, $\beta_{1}$ effect that Medicare has on dementia.

Since we are trying to test whether Medicate eligibility is causally responsible for dementia symptoms reductions in Eq. (7), we are not going to include any behavioural variables in our list of $Z$ variables that we included in Eq. (5) (though we are going to include education as that was separately shown to be exogenous in the education dementia study). The literature has shown that lifestyle variables (such as alcohol, smoking, blood pressure and obesity) are associated with dementia symptoms. But, these associations may be due to reverse causation 
and thus not helpful for our current purpose. For Eq. (7) then we will focus just on demographic and hereditary variables that are by design exogenous.

\section{The description of all the variables used in the study and the data summary}

All the variables used in the two estimation equations are listed in Table 1 together with their definitions. The definitions come from NACC's 'Description of NACC-Derived Variables to be Used in Data Analysis' and NACC's UDS 'Coding Guidebook for Initial Visit Packet'. The data set used in this study included only information on the initial visit, so each observation is for a separate individual. When there were no missing data, there were 17,341 observations.

Table 2 gives the data summary in terms of the number of observations, mean values, SDs, and minimum and maximum values. We can see that the average age was 72 years and over three-quarters of the sample were eligible for Medicare. The typical severity of dementia symptoms was mild with the average CDR-SB score of 3.1 when the score for the worst cases was 18 . Most of the people in the sample were married and female. The average number of years of education was high at 15 years. Two-thirds of the people in the sample were living independently.

The QoL as measured by the GDS total score was effectively good for most persons, averaging 1.81 when the most severe cases would have a score of 15 . The 15 individual components of the total GDS are also displayed in Table 2. The GDS score for energy had the highest score (in this case, meaning a lack of energy, with an average for GDS13 of 0.28) and the GDS score was lowest for feeling hopeless (with an average for GDS 14 of 0.07).

\section{Estimation results}

Estimates for the three components represented in Eq. (1) will be presented separately and then they will be multiplied together to obtain the benefits of Medicare eligibility.

\section{Component 1: the effect of changes in independent living levels on costs}

When dementia symptoms reductions increased independent living $L_{1}$, the three more costly forms of dependent living $L_{2}, L_{3}$ and $L_{4}$ went down. The unit costs estimates for the three dependent living levels set out in Eq. (2) that we shall be using come from the education dementia CBA derived from Hurd, Martorell, and Delavande et al. (2013). The estimates were

$$
\begin{aligned}
\frac{\partial C}{\partial L 2} & =\$ 13,188, \frac{\partial C}{\partial L 3}=\$ 27,789, \frac{\partial C}{\partial L 4} \\
& =\$ 28,501
\end{aligned}
$$


When dependent living involves assistance only when activities are complex, the support costs are about half as much as when a person requires support with simple tasks or is completely dependent.

\section{Component 2: the effect of changes in dementia on independent living}

GDS, as the dependent variable in the utility function specified by Eq. (5), takes the form of a discrete count variable. To use the Poisson model, the mean and variance must be the same. In our data, the mean for GDS was 1.81 and the variance was 5.48. To accommodate this over dispersion, the Negative Binomial (Neg Bin) distribution can be adopted. The result of using the Neg Bin to estimate equation (5) is displayed as the first column of Table 3. The alpha value for this regression was estimated to be 0.9470 and significantly different from zero, which is the value that the Poisson Distribution is constrained to be. The Neg Bin model was therefore found to be more appropriate than the Poisson distribution for our data.

As expected, dementia is positively related to GDS and therefor negatively related to utility. All three dependent living variables were statistically significant determinants of utility (at least at the 5\% level) as negatively proxied by the GDS. Somewhat surprisingly, living completely dependent on others, $L 4$, had the lowest effect on the GDS and hence the lowest negative impact on utility. The negative impact of $L 2$ on utility was the highest with $L 3$ 's impact being in between. Being married and affected by alcohol raised utility; while having a high heart rate and smoking for more years lowered utility. Being eligible for Medicare raised utility even though becoming older than 65 reduced a person's utility.

It is the MRSs for the three dependent living levels that determine the second component of the benefits formula corresponding to Eq. (6) and they are shown at the bottom of Table 3. From the Neg Bin regression we obtain

$$
\begin{aligned}
\frac{\partial L 2}{\partial D} & =0.1033 ; \frac{\partial L 3}{\partial D}=0.1200 ; \text { and } \frac{\partial L 4}{\partial D} \\
& =0.1920
\end{aligned}
$$

These results reveal that the impact of dementia symptoms was the greatest on $L 4$ and lowest for $L 2$. Although all four coefficients that make up the estimates in Eq. (10) were individually highly significant, it is the significance of the ratios that is important for estimating component 2 . Using a non-linear Wald, chi-square test, that the null for the ratios of the two regression coefficients were zero, we could reject the null at $1 \%$ for the MRS estimates for $L 2$ and $L 3$, but only at the $10 \%$ level for $L 4$.

To see what difference it makes to the results if individual components of the GDS were used as the dependent variable instead of the total GDS score, Table 3 also reports Probit estimates for the three GDS ingredients that produced statistically significant alternative results for the $a$ coefficients. GDS2 ('choosing to give up activities') and GDS12 ('feeling pretty worthless') produced lower MRS estimates and GDS15 ('thinking that others are better off') gave higher MRS estimates than for the total GDS score. How these alternative 
GDS estimates altered the total benefit amounts is analysed in the 'Sensitivity analysis' section.

\section{Component 3: estimating the effect of medicare on dementia}

Although our measure of dementia symptoms CDR-SB, the dependent variable in Eq. (7), appears to be a discrete count variable, and potentially amenable for estimation by using Poisson regression, this was not the case because CDR-SB is scored 0.5 whenever five of the six categories (boxes) were considered 'questionable' for a client. Many of the observations had CDR-SB scores ending with 0.5. Simple OLS was therefore the estimation technique adopted and Table 4 shows the RD results.

The results that we will be using as our main estimates for the third component come from the varying slopes RD regression equation. However, for reference, we also include in Table 4 the regression estimates for the basic model where that is no interaction term.

Substituting the coefficients from the varying slopes RD regression model into Eq. (8), we obtain

$$
\frac{\partial D}{\partial M}=-0.9182+0.1079(\text { Age }-65)
$$

As expected, $\beta_{1}$ is negative and $\beta_{3}$ is positive. The impact of Medicare eligibility on dementia starts off at -0.9182 and becomes less negative by 0.1079 for every year the client is over 65 years. Thus, the initial effect of Medicare at the year of eligibility is to reduce dementia symptoms by 0.9182 and this tails off to a 0.1327 reduction at age 72.27 , which is the average age of clients in our sample.

This estimate of the third component comes from a regression equation which explains about $20 \%$ of the variation in dementia, which is quite high for a cross-sectional study with a large number of observations and a dependent variable that varies widely from individual to individual. The statistically significant controls other than years of education (in log form) and gender (being male) were the set of hereditary variables, that is, whether one had one or two copies of APOE (the e4 allele from one or both of the parents), whether one had a sibling with dementia, and one's height.

If we had not used the varying slopes RD design, there would have only have been the initial dementia symptoms reduction effect given by $\beta_{1}$. As we see from Table 4 , the initial Medicare eligibility effect without the interaction term would have been -1.3173 . This is slightly higher than our varying slopes estimate which was -0.9182 . However, it still indicates around a 1-point reduction in dementia symptoms. The explanatory powers of the basic RD design at 19\% was almost as high as for the varying slopes design. But the basic RD model imposes the restriction that the slope of the assignment variable with respect to dementia symptoms before the cut-off point is the same as after the cut-off point, which Figure 1 shows is not the case. 
Figure 1 maps the assignment variable against the dementia rating. Being eligible for Medicare lowers dementia symptoms by almost one point. This figure also confirms visually the fact that the slope of the assignment variable after the age 65 cut-off is much greater than before the cut-off age. From Table 4 we see that the slope for the assignment variable before 65 years, $\beta_{2}$, was only 0.0378 ; while the slope for the assignment variable after 65 years was almost four times greater at 0.1457 (the sum of $\beta_{2}$ and $\beta_{3}$ ). Figure 1 thus confirms our earlier intuition that the varying slopes RD model is the more appropriate one as it allows the initial Medicare eligibility effect to decline over time, which is what the results in Eq. (11) imply.

\section{Testing the assumptions of the RD model}

For the RD to be truly a causal model for Medicare on dementia symptoms, it is important that the assignment variable not behave peculiarly at the cut-off point. If clients have any control of the cut-off point, there is scope for clients to 'game' the system. In which case Medicare eligibility would not be the reason for the jump at the cut-off age. In our case, there is no (legal) way that clients can manipulate getting over the threshold. But, it is still logically possible that in our sample more people just over 65 happen to appear in our data set as they are more vulnerable to being affected by dementia. To check for this remote possibility, we present a histogram in Figure 2 that shows the relative frequency of the assignment variable by age. It is apparent that there is no clustering with a bump at the cutoff age of 65 . No gaming actually occurred.

The other main concern with RD models is that other variables than Medicare jump at the cut-off age. If so, then Medicare may not be causal for the threshold jump to dementia and these other variables could be. The diagnostic test for this concern involves regressing any control variable $Z$ on the variables in the RD model to see whether the coefficient on $M$ is statistically significant or not. For the varying slopes RD model, the test regression is

$$
\begin{array}{r}
Z=\delta_{0}+\delta_{1} M+\delta_{2}(\text { Age }-M) \\
\left.+\delta_{3}(\text { Age }-M)\right) \times M+\varphi
\end{array}
$$

where $Z$ is the set of non-Medicare controls and $\delta_{1}$ is the coefficient of interest. If $\delta_{1}$ is statistically significant then the $Z$ variable jumps at the discontinuity and not just Medicare.

Given that education was the only control variable that was behavioural (all the others were hereditary), we will concentrate just on the test for this variable as this is the only control variable that could jump at 65 years. ${ }^{6}$ The estimate for $\delta_{1}$ with log education as the dependent variable was -0.0067 with a $t$-statistics of 0.58 . This coefficient had a $p$-value of 0.569 and so was not remotely significant.

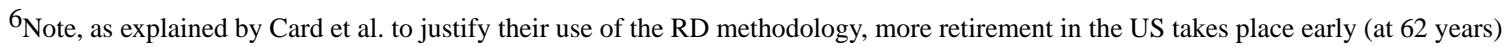
then at the full benefit age for Social Security that was 65 years. So the effect of Medicare eligibility at 65 years is not masked by retirement at 65 years (which is a variable that we could not control for in our study). In any case, retirement is less likely to be a consideration for an at-risk dementia population who probably would not be working.
} 


\section{The total benefits estimate}

The three-component benefit method was set out in Eq. (2) and the estimates of the components were given in Eq. (9)-(11). Table 5 reproduces the estimates for the three components for each of the dependent living levels and multiplies them together to form the benefits for each level. The total benefits are the sum of the three benefit components. Table 5 gives the results for two time periods according to two different estimates for component 3. The first time period is when Medicare eligibility is first initiated at year 65 , where the value for component 3 is given just by the coefficient $\beta_{1}$ equal to -0.9182 . The second time period is 7.28 years after first initiation, when the client is around 72 years of age.

Multiplying coefficient $\beta_{1}$ by 7.28 produces the 0.1327 figure that we explained earlier in connection with Eq. (11).

Note that for simplicity of interpretation, component 3 is recorded in Table 5 as a positive amount. That is because we are using cost reductions to measure benefits. The cost figures in component 1 are being reduced, to the extent indicated by component 2 , because dementia symptoms are being lowered by Medicare eligibility, given by component 3 . The simplification then is that costs changes are negative and the dementia symptoms changes are also negative producing a positive sum when multiplied together.

The total benefits were $\$ 9338$ per Medicare eligible person at age 65 years, which fall to $\$ 1350$ when the client is aged 72.28. Over half of these total amounts comes from the completely dependent living category $L 4$, which is the costliest and therefore provides the greatest cost savings. $L 4$ is also the category of dependent living that is most affected by dementia symptoms being reduced.

\section{Sensitivity analysis}

Given that the main methodological contribution of the article involves using the utility function to estimate component 2 , the sensitivity analysis will focus on alternative estimates to those in Table 5 stemming from the way dementia impacts independent living levels $\frac{\partial L i}{\partial D}$. The best estimate for component 2 came from the Negative Binomial regression for Eq. (5) in Table 3 using GDS as the proxy for $U$. The first set of alternative results entail using the individual ingredients of the GDS rather that the summary measure. As we can see from Table 3, there were three GDS ingredients that produced statistically significant alternative estimates for the $a$ coefficients and these were GDS2, GDS12 and GDS15. ${ }^{7}$ The alternative benefit estimates using these three ingredients' results for component 2 are displayed in the first three sections of Table 6. For ease of comparison, we report the alternative results to those in Table 5 just for the Medicare benefits at the year of eligibility.

Instead of the best estimates $0.1033,0.1200$ and 0.1920 for changes in $D$ on $L 2, L 3$ and $L 4$, respectively, the ratios for GDS2 and GDS12 were lower, and they were higher for GDS 15

\footnotetext{
${ }^{7}$ Although using GDS1 and GDS7 as GDS alternatives would have been preferable on 'a priori' grounds, as explained in the 'The measure of quality of life' section, they did not in fact produce statistically significant estimates for component 2 . So they could not be included as alternative specifications of the total GDS for the purposes of the sensitivity analysis. But, note that the correlation between GDS12 ('feeling pretty worthless') and the total GDS (being 0.5864) was almost as high as GDS1 and GD7 (0.5950 and 0.5993), so GDS12 was nonetheless a good proxy for GDS total.
} 
(see the bottom section of Table 3). The best estimate of the total benefits in our main results was $\$ 9338$. This estimate was not consistently higher or lower than the alternative benefit estimates which were $\$ 7258, \$ 3458$ and $\$ 10,109$. So the orders of magnitude for the three alternatives shown in Table 6 were very roughly the same as for the best estimate in Table 5 (except for GDS12 which was much lower).

The fourth and final alternative was to not use the utility function at all, but to substitute estimates coming from the production function which involves regressing $D$ directly on the $L i$. This was the method carried out in the education dementia study. The three estimates coming from Table 4 of the education dementia study were much lower than for the best estimates in this study which were 0.0278 (instead of 0.1033), 0.0199 (instead of 0.1200) and 0.0064 (instead of 0.1920 ). Consequently, the total benefits using the production function were $\$ 1012$, considerably lower than the $\$ 9338$ best estimate. It seems that mechanically seeing how independent living levels are altered by reductions in dementia symptoms undervalues the benefits, as it ignores people's preferences that entail the satisfaction from Medicare that makes them more willing to sacrifice independent living to achieve a reduction in dementia symptoms.

\section{Discussion}

This study is a companion piece to the education dementia CBA that was one of the first to estimate the benefits for an intervention that (a) causally impacted dementia and (b) did so in a way that acted as treatment (mitigating the symptoms) rather than prevention (delaying the costs of the disease). Here we identified Medicare eligibility as another causal intervention for dementia symptoms and again estimated the monetary benefits of the intervention.

The method we used to monetize the benefits was the same as for the education dementia CBA which involved estimating three components: the extent to which an intervention lowered dementia as measured; the extent to which lowering dementia symptoms promotes more independent living; and the extent to which promoting independent living leads to caregiving cost savings. The methodological contribution of this study is that we estimated the second component by using a patient's utility function and finding the MRS between dementia symptoms and dependent living in this utility function. In this way, any cost savings that came from changes in dependent living reflected the preferences of the patients, rather than being a mechanical production function effect that has changed living conditions as an output corresponding to reductions in dementia symptoms as an input. For the third component, we borrowed the RD identification strategy employed by Card et al. (2008, 2009) to estimate the health effects of having Medicare eligibility; and for the first component, we adopted dependent living costs coming from the dementia literature.

Our best estimate of the total benefits of Medicare at the year of eligibility was around $\$ 9338$ per person in 2010 prices and this fell to $\$ 1350$ seven years subsequently when a client was around 72 years. To give some perspective on the size of these benefits, and to carry out the beginnings of a CBA, we can refer to the Medicare cost figures calculated by Zissimopoulos, Crimmins, and St.Clair (2015), Table 1. For 2010, the per capita Medicare annual cost per person was $\$ 10,904$ if an individual aged $70+$ did not have $\mathrm{AD}$ and it was 
$\$ 17,444$ if the individual did have AD. The difference in these two cost figures, which is $\$ 6540$, approximates the additional cost to Medicare if someone's dementia symptoms are not reduced. Compared to this cost, the estimated $\$ 9338$ benefits of initial Medicare eligibility lowering dementia symptoms are relatively large. The estimated benefits of Medicare eligibility on their own outweigh the costs, at least for the first few years after eligibility. Moreover, Medicare eligibility has many other types of healthcare benefits, as exemplified by the morality reductions found by Card et al. These monetary benefits need to be added to our estimates. In addition, caregiver benefits have not been estimated in our study and these are also sizeable; one estimate has the benefits to caregivers of the complete prevention of $\mathrm{AD}$ at around $\$ 2275$ per year. ${ }^{8}$ With just these additional benefits estimates, the total benefits of Medicare eligibility 7 years after the age of 65 would amount to $\$ 3625$, which covers around 55\% of the annual cost of including dementia clients in Medicare.

From the Public Policy point of view, it is necessary that effective and worthwhile interventions for combatting dementia are identified. However, it is also very important to try to understand why and how any intervention, in our case Medicare eligibility, achieves its results. On this issue, the work by Card et al. provides some useful clues. To help explain why Medicare eligibility was so effective in reducing emergency mortalities, they point out that one cannot just focus on the number of persons who newly acquire health insurance when they turn 65 years of age. Although over $80 \%$ of the population enrolls in the Medicare programme within a few weeks of turning 65 years of age, much of this is crowdout from private insurance plans. The rise in the fraction of the people who at the age of 65 newly acquire health insurance is only 9 percentage points.

But, the fraction of the population with multiple policies (public and private) rises by 45 percentage points as those with private coverage pre-65 supplement their Medicare coverage. In either case, whether through new insurance or expanded coverage, the post- 65 group are receiving more, and possibly higher quality, services than before and this is one explanation for how the success of Medicare eligibility in reducing mortality came about. Although we do not have any real evidence in the case of dementia, it is possible that not only patients but also caregivers are receiving better support services once they are eligible for Medicare in line with the rest of the post-65 population, and this may have led to the dementia symptoms reduction observed.

Nonetheless, we can add something to the Card et al. story that arises from the findings in our study by way of the second component in our benefits formula. To estimate how dependent living $L \mathrm{i}$ changed when dementia symptoms $D$ was reduced, we estimated the person's utility function, which depended on $L$ i and $D$ and a set of controls $Z$. One of the controls was Medicare $M$. Thus, our estimate of the MRS between $D$ and $L \mathrm{i}$ was conditional on the person being eligible for Medicare or not. We can see from Table 3 that $M$ had a very strong, statistically significant, positive effect on the $\mathrm{QoL}$ of the patients (our negative proxy for utility using the GDS was reduced by $M$ ). Let us focus on $L 4$ which was the most dependent living state. The reduction in $D$ had a large impact on $L 4$ and this led to large

\footnotetext{
${ }^{8}$ See Basu (2013). His estimate was $\$ 155$ per month in 2002 prices. This is equivalent to $\$ 1860$ per year, which is $\$ 2275$ in 2010 prices (using a CPI inflator of 1.2235).
} 
cost-savings. The MRS could have been so large because Medicare increased the QoL and this made it possible for the person to be more willing to accept a large amount of dependent living in exchange for any reduction in dementia symptoms that Medicare eligibility brought about.

\section{Acknowledgments}

Funding

The NACC database is funded by NIA/NIH [Grant U01 AG016976]. NACC data are contributed by the NIAfunded ADCs: P30 AG019610 (PI Eric Reiman, MD), P30 AG013846 (PI Neil Kowall, MD), P50 AG008702 (PI Scott Small, MD), P50 AG025688 (PI Allan Levey, MD, PhD), P30 AG010133 (PI Andrew Saykin, PsyD), P50 AG005146 (PI Marilyn Albert, PhD), P50 AG005134 (PI Bradley Hyman, MD, PhD), P50 AG016574 (PI Ronald Petersen, MD, PhD), P50 AG005138 (PI Mary Sano, PhD), P30 AG008051 (PI Steven Ferris, PhD), P30 AG013854 (PI M. Marsel Mesulam, MD), P30 AG008017 (PI Jeffrey Kaye, MD), P30 AG010161 (PI David Bennett, MD), P30 AG010129 (PI Charles DeCarli, MD), P50 AG016573 (PI Frank LaFerla, PhD), P50 AG016570 (PI David Teplow, PhD), P50 AG005131 (PI Douglas Galasko, MD), P50 AG023501 (PI Bruce Miller, MD), P30 AG035982 (PI Russell Swerdlow, MD), P30 AG028383 (PI Linda Van Eldik, PhD), P30 AG010124 (PI John Trojanowski, MD, PhD), P50 AG005133 (PI Oscar Lopez, MD), P50 AG005142 (PI Helena Chui, MD), P30 AG012300 (PI Roger Rosenberg, MD), P50 AG005136 (PI Thomas Montine, MD, PhD), P50 AG033514 (PI Sanjay Asthana, MD, FRCP) and P50 AG005681 (PI John Morris, MD).

\section{References}

Arons AMM, Krabbe PFM, Scholzel-Dorenbos CJM et al. 2013 "Quality of Life in Dementia: A Study on Proxy Bias.” BMC Medical Research Methodology 13:110. [PubMed: 24011428]

Basu R 2013 “Willingness-To-Pay to Prevent Alzheimer's Disease: A Contingent Valuation Approach.” International Journal of Health Care Finance and Economics 13: 233-245. [PubMed: 23996130]

Beekly DL, Ramos ER, Lee WW et al. 2007 “The National Alzheimer's Coordinating Center (NACC) Database: The Uniform Data Set.” Alzheimer Disease and Associative Disorders 21:249-258.

Besser LM, Gill DP, Monsell SE et al. 2014 "Body Mass Index, Weight Change and Clinical Progression in Mild Cognitive Impairment and Alzheimer's Disease.” Alzheimer Disease and Associative Disorders 28:36-43.

Brent RJ 2006 Applied Cost-Benefit Analysis. Second ed. Cheltenham, UK: Edward Elgar.

Brent RJ 2014 Cost-Benefit Analysis and Health Care Evaluations. Second ed. Cheltenham, UK: Edward Elgar.

Brent RJ 2017 “The Value of a Year's General Education for Reducing the Symptoms of Dementia.” Applied Economics. doi:10.1080/00036846.2017.1409420.

Burke SL, Maramaldi P, Cadet T et al. 2016 “Associations between Depression, Sleep Disturbance, and Apolipoprotein E in the Development of Alzheimer's Disease: Dementia." International Psychogeriatrics 28:1409-1424. [PubMed: 27020605]

Card D, Dobkin C, and Maestas N. 2008 "The Impact of Nearly Universal Health Insurance Coverage on Health Care Utilization: Evidence from Medicare.” American Economic Review 98: 2242-2258. [PubMed: 19079738]

Card D, Dobkin C, and Maestas N. 2009 “Does Medicare Save Lives?” Quarterly Journal of Economics 124: 597-636. [PubMed: 19920880]

Graham C 2010 Happiness around the World: The Paradox of Happy Peasants and Miserable Millionaires. New York: Oxford University Press.

Hurd MD, Martorell P, Delavande A et al. 2013 "Monetary Costs of Dementia in the United States." New England Journal of Medicine 368:1326-1334. [PubMed: 23550670]

Logsdon RG, Gibbons LE, McCurry SM et al. 2002 "Assessing Quality of Life in Older Adults with Cognitive Impairment.” Psychosomatic Medicine 64:510-519. [PubMed: 12021425] 
Long KH, Moriarty JP, Mittelman MS et al. 2014 "Estimating the Potential Cost Savings from the New York University Caregiver Intervention in Minnesota.” Health Affairs 33:596-604. [PubMed: 24711320]

Morris JC, Weintraub S, and Chui HC. 2006 "The Uniform Data Set (UDS): Clinical and Cognitive Variables and Descriptive Data from Alzheimer Disease Centers.” Alzheimer Disease and Associative Disorders 20: 210-216.

Schiffczyk C, Jonas C, Lahmeyer C et al. 2011 "Gender Dependence of Substituted Judgment on Quality of Life in Patients with Dementia.” BMC Neurology 11:118. [PubMed: 21961477]

Vagetti GC, Barbosa Filho VC, Moreira NB et al. 2014 "Association Between Physical Activity and Quality of Life in the Elderly: A Systematic Review, 2000-2012.” Revista Brasileira De Psiquiatria 36:76-88. [PubMed: 24554274]

Weimer D, and Sager M. 2009 "Early Identification of Alzheimer's Disease (2009): Social and Fiscal Outcomes.” Alzheimer's \& Dementia 5: 215-226.

Weintraub S, Salmon D, Mercaldo N et al. 2009 “The Alzheimer's Disease Centers' Uniform Data Set (UDS): The Neuropsychological Test Battery.” Alzheimer Disease and Associative Disorders 23:91.

World Alzheimer Report 2014: Dementia and Risk Reduction: An Analysis of Protective and Modifiable Factors. Alzheimer's Disease International, 2014.

World Alzheimer Report 2014: The Global Impact of Dementia: An Analysis of Prevalence, Incidence, Cost and Trends. Alzheimer's Disease International, 2015.

Zhu CW, Scarmeas N, Stavitsky K et al. 2008 "Comparisons of Costs of Care between Patients with Alzheimer's Disease and Dementia with Lewy Bodies.” Alzheimer's \& Dementia 4:280-284.

Zissimopoulos J, Crimmins E, and St.Clair P. 2015 “The Value of Delaying Alzheimer's Disease Onset." Forum for Health Economics and Policy 18: 25-39. 


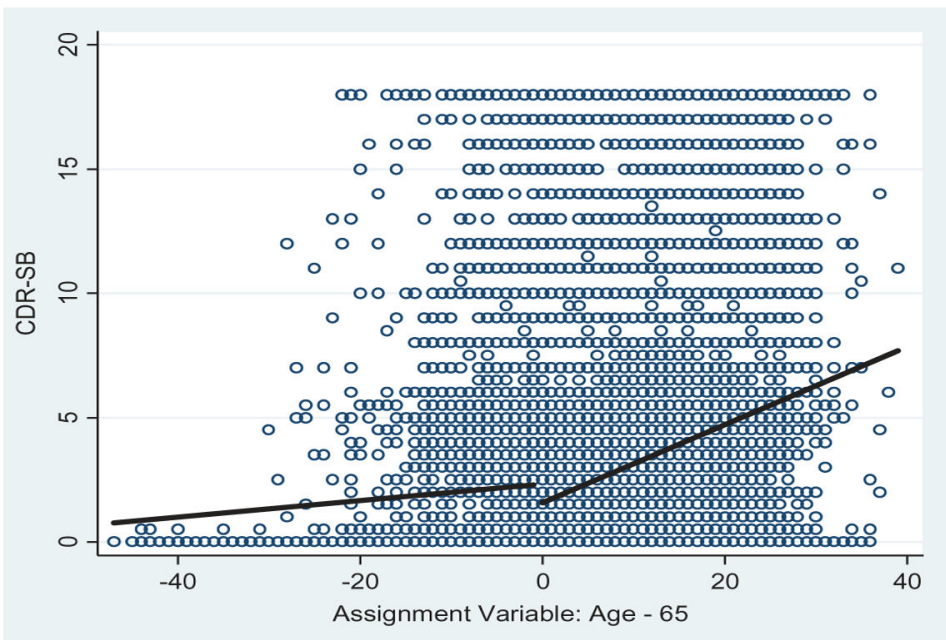

Figure 1.

Plot for the assignment variable on CDR-SB. 


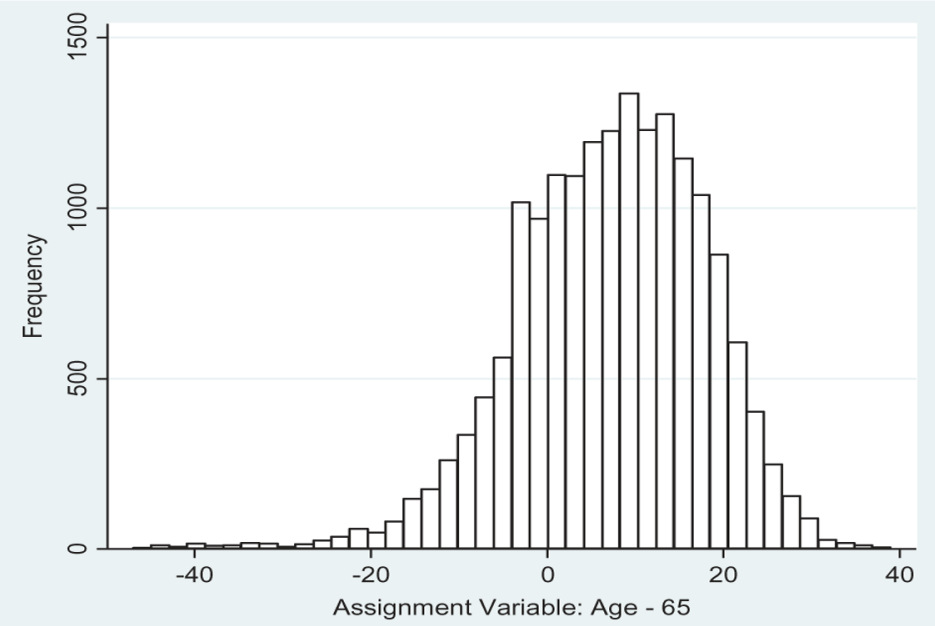

Figure 2.

Histogram for the assignment variable on CDR-SB. 


\section{Table 1}

\section{Definitions of all variables.}

\begin{tabular}{|c|c|}
\hline Variable & Description \\
\hline Medicare $M$ & $\begin{array}{l}\text { Is the subject eligible for Medicare? } \\
\text { Age } \geq 65=1 ; \text { Age }<65=0\end{array}$ \\
\hline CDR-SB & $\begin{array}{l}\text { Clinical Dementia Rating (CDR) Sum of Boxes (SB). } \\
\text { Total CDR score based on Memory, Orientation, Judgement \& Problem Solving, Community Affairs, Home } \\
\& \\
\text { Hobbies, Personal Care, each of the six categories on a scale of } 0 \text { to } 3 \text {, with } 0 \text { for none, } 1 \text { for mild, } 2 \text { for } \\
\text { moderate } \\
\text { and } 3 \text { for severe. }\end{array}$ \\
\hline$($ Age -65$)$ & Assignment variable $=$ Age - Cut-off. \\
\hline$($ Age -65$) \times M$ & Assignment variable $\times$ Treatment $=($ Age - Cut-off $) \times$ M. \\
\hline Education & Subject's years of education completed. \\
\hline Age & Subjects age at initial visit. \\
\hline Male & Subject's sex: \\
\hline & Male $=1$, Female $=0$ \\
\hline Smoke & $\begin{array}{l}\text { Total number of years the subject has smoked: } \\
\text { Zero is } 0 \text { years smoked or not applicable. }\end{array}$ \\
\hline Alcohol & $\begin{array}{l}\text { Alcohol Impairment: } \\
1 \text { = Clinically significant impairment occurring over a 12-month period manifested in one of the following: } \\
\text { work, } \\
\quad \text { driving, legal or social. } \\
0=\text { No impairment. }\end{array}$ \\
\hline $\begin{array}{l}\text { Geriatric Depression Scale } \\
\text { (GDS) }\end{array}$ & $\begin{array}{l}\text { Total GDS score: } \\
\text { Sum of the } 1 \mathrm{~s} \text { for the } 15 \text { ingredients of the GDS. }\end{array}$ \\
\hline GDS1 & $\begin{array}{l}\text { Are you basically satisfied with your life? } \\
\text { Yes }=0, \text { No }=1\end{array}$ \\
\hline GDS2 & $\begin{array}{l}\text { Have you dropped many of your activities and interests? } \\
\text { Yes }=1, \text { No }=0\end{array}$ \\
\hline GDS3 & $\begin{array}{l}\text { Do you feel that your life is empty? } \\
\text { Yes }=1, \text { No }=0\end{array}$ \\
\hline GDS4 & $\begin{array}{l}\text { Do you often get bored? } \\
\text { Yes }=1, \text { No }=0\end{array}$ \\
\hline GDS5 & $\begin{array}{l}\text { Are you in good spirits most of the time? } \\
\text { Yes }=0, \text { No }=1\end{array}$ \\
\hline GDS6 & Are you afraid that something bad is going to happen to you? Yes $=1$, No $=0$. \\
\hline GDS7 & $\begin{array}{l}\text { Do you feel happy most of the time? } \\
\text { Yes }=0, \text { No }=1\end{array}$ \\
\hline GDS8 & Do you often feel helpless? Yes $=1$, No $=0$. \\
\hline GDS9 & Do you prefer to stay at home, rather than going out and doing new things? Yes $=1$, No $=0$. \\
\hline GDS10 & Do you feel you have more problems with memory than most? Yes $=1$, No $=0$. \\
\hline GDS11 & $\begin{array}{l}\text { Do you think it is wonderful to be alive now? } \\
\text { Yes }=0, \text { No }=1\end{array}$ \\
\hline GDS12 & $\begin{array}{l}\text { Do you feel pretty worthless the way you are now? } \\
\text { Yes }=1 \text {, No }=0 \text {. }\end{array}$ \\
\hline GDS13 & $\begin{array}{l}\text { Do you feel full of energy? } \\
\text { Yes }=0, \text { No }=1\end{array}$ \\
\hline GDS14 & $\begin{array}{l}\text { Do you feel that your situation is hopeless? } \\
\text { Yes }=1 \text {, No }=0 \text {. }\end{array}$ \\
\hline GDS15 & $\begin{array}{l}\text { Do you think that most people are better off than you are? } \\
\text { Yes }=1, \text { No }=0 \text {. }\end{array}$ \\
\hline
\end{tabular}




\begin{tabular}{ll}
\hline Variable & \multicolumn{1}{c}{ Description } \\
\hline APOE (one copy) & Number of Apolipoprotein E (APOE) copies. \\
& $1=1$ copy of e4 allele; 0 = No e4 allele copy or 2 e4 allele. copies. \\
& Number of Apolipoprotein E (APOE) copies \\
APOE (two copies) & $1=2$ copies of e4 allele; 0 = No e4 allele copy or 1 e4 allele copy. \\
& Subject's resting heart rate (pulse). \\
Heart rate & The subject's level of independence: \\
Independence living level & 2= Able to live independently; \\
& $3=$ Requires some assistance with complex activities; \\
& $4=$ Completely dependent; \\
& Subjects current marital status: \\
Marital status & Married = 0, All others = 0. \\
\hline
\end{tabular}


Table 2

Descriptive statistics for all the variables.

\begin{tabular}{|c|c|c|c|c|c|}
\hline Variable & Number & Mean & SD & Minimum & Maximum \\
\hline Medicare $M$ & 17,341 & 0.78 & 0.41 & 0 & 1 \\
\hline CDR-SB & 17,341 & 3.08 & 4.46 & 0 & 18 \\
\hline$(\mathrm{Age}-65)$ & 17,341 & 7.28 & 10.75 & -47 & 39 \\
\hline$($ Age -65$) \times M$ & 17,341 & 8.99 & 7.91 & 0 & 39 \\
\hline Education & 17,239 & 14.93 & 3.51 & 0 & 28 \\
\hline Log education & 17,203 & 2.67 & 0.30 & 0 & 3 \\
\hline Age & 17,341 & 72.28 & 10.75 & 18 & 104 \\
\hline Male & 17,341 & 0.42 & 0.49 & 0 & 1 \\
\hline Smoke & 17,341 & 9.63 & 15.28 & 0 & 85 \\
\hline Alcohol & 17,292 & 0.95 & 0.21 & 0 & 1 \\
\hline GDS (total score) & 15,957 & 1.81 & 2.34 & 0 & 15 \\
\hline GDS1 & 15,954 & 0.10 & 0.30 & 0 & 1 \\
\hline GDS2 & 15,953 & 0.19 & 0.39 & 0 & 1 \\
\hline GDS3 & 15,952 & 0.07 & 0.26 & 0 & 1 \\
\hline GDS4 & 15,953 & 0.13 & 0.34 & 0 & 1 \\
\hline GDS5 & 15,949 & 0.06 & 0.23 & 0 & 1 \\
\hline GDS6 & 15,951 & 0.09 & 0.29 & 0 & 1 \\
\hline GDS7 & 15,949 & 0.09 & 0.28 & 0 & 1 \\
\hline GDS8 & 15,951 & 0.09 & 0.29 & 0 & 1 \\
\hline GDS9 & 15,949 & 0.23 & 0.42 & 0 & 1 \\
\hline GDS10 & 15,944 & 0.27 & 0.44 & 0 & 1 \\
\hline GDS11 & 15,946 & 0.04 & 0.20 & 0 & 1 \\
\hline GDS12 & 15,943 & 0.07 & 0.25 & 0 & 1 \\
\hline GDS13 & 15,944 & 0.28 & 0.45 & 0 & 1 \\
\hline GDS14 & 15,949 & 0.04 & 0.20 & 0 & 1 \\
\hline GDS15 & 15,946 & 0.07 & 0.25 & 0 & 1 \\
\hline APOE (one copy) & 11,790 & 0.35 & 0.48 & 0 & 1 \\
\hline APOE (two copies) & 11,790 & 0.07 & 0.26 & 0 & 1 \\
\hline Heart rate & 15,863 & 68.48 & 10.80 & 36 & 159 \\
\hline Independence & 17,299 & 1.56 & 0.85 & 1 & 4 \\
\hline Independence level 1 & 17,299 & 0.63 & 0.48 & 0 & 1 \\
\hline Independence level 2 & 17,299 & 0.22 & 0.41 & 0 & 1 \\
\hline Independence level 3 & 17,299 & 0.11 & 0.31 & 0 & 1 \\
\hline Independence level 4 & 17,299 & 0.04 & 0.20 & 0 & 1 \\
\hline Marital status & 17,237 & 0.61 & 0.49 & 0 & 1 \\
\hline
\end{tabular}

Appl Econ. Author manuscript; available in PMC 2018 October 19. 


\section{Table 3}

Effect on GDS of CDR-SB and independence living.

\begin{tabular}{|c|c|c|c|c|}
\hline \multirow[b]{2}{*}{ Variable } & \multicolumn{4}{|c|}{$\underline{\text { Dependent variable with estimation technique }}{ }^{a, b}$} \\
\hline & GDS Neg Bin & GDS2 Probit & GDS12 Probit & GDS15 Probit \\
\hline CDR-SB: $a_{\mathrm{D}}$ & $\begin{array}{l}0.0416^{* * * *} \\
\quad(6.11)\end{array}$ & $\begin{array}{l}0.0096 * * * \\
(4.82)\end{array}$ & $\begin{array}{l}0.0037 * * * \\
\quad(4.00)\end{array}$ & $\begin{array}{l}0.0057 * * * \\
\quad(7.77)\end{array}$ \\
\hline Independent level 2: $a_{\mathrm{L} 2}$ & $\begin{array}{l}0.4026 * * * \\
\quad(8.72)\end{array}$ & $\begin{array}{l}0.1377 * * * \\
(8.21)\end{array}$ & $\begin{array}{l}0.0549 * * * \\
\quad(6.40)\end{array}$ & $\begin{array}{l}0.0361 * * * \\
\quad(5.14)\end{array}$ \\
\hline Independent level 3: $a_{\mathrm{L} 3}$ & $\begin{array}{l}0.3464 * * * \\
\quad(5.81)\end{array}$ & $\begin{array}{l}0.0992 * * * \\
\quad(3.75)\end{array}$ & $\begin{array}{l}0.0698^{* * * *} \\
\quad(5.40)\end{array}$ & $\begin{array}{l}0.0481 * * * \\
\quad(3.97)\end{array}$ \\
\hline Independent level 4: $a_{\mathrm{L} 4}$ & $\begin{array}{l}0.2165^{* *} \\
(2.06)\end{array}$ & $\begin{array}{c}0.0633 \\
(1.58)\end{array}$ & $\begin{array}{l}0.0742 * * * \\
\quad(2.72)\end{array}$ & $\begin{array}{l}0.0426 * * * \\
\quad(3.01)\end{array}$ \\
\hline Marital status & $\begin{array}{c}-0.1816^{* * *} \\
(6.14)\end{array}$ & $\begin{array}{l}-0.0246^{* * * *} \\
(3.24)\end{array}$ & $\begin{array}{l}-0.0134 * * * \\
\quad(3.28)\end{array}$ & $\begin{array}{l}-0.0251 * * * \\
\quad(4.32)\end{array}$ \\
\hline Smoke & $\begin{array}{l}0.0040 * * * \\
(4.72)\end{array}$ & $\begin{array}{l}0.0011 * * * \\
\quad(5.20)\end{array}$ & $\begin{array}{l}0.0005^{* * *} \\
(5.11)\end{array}$ & $\begin{array}{l}0.0001 \\
(0.72)\end{array}$ \\
\hline Alcohol & $\begin{array}{c}-0.2443^{* * *} \\
(4.74)\end{array}$ & $\begin{array}{l}-0.0553 * * * \\
(4.57)\end{array}$ & $\begin{array}{c}-0.0124 \\
(1.29)\end{array}$ & $\begin{array}{l}-0.0199 * * * \\
(2.85)\end{array}$ \\
\hline Heart rate & $\begin{array}{l}0.0550 * * * \\
\quad(4.37)\end{array}$ & $\begin{array}{l}0.0013 * * * \\
(4.10)\end{array}$ & $\begin{array}{c}0.0002 \\
(1.21)\end{array}$ & $\begin{array}{c}0.0002 \\
(1.90)\end{array}$ \\
\hline Medicare $M$ & $\begin{array}{l}-0.3217 * * * \\
(7.51)\end{array}$ & $\begin{array}{c}-0.0732 * * * \\
\quad(4.50)\end{array}$ & $\begin{array}{l}-0.0416 * * * \\
(5.54)\end{array}$ & $\begin{array}{l}-0.0295 * * * \\
\quad(3.82)\end{array}$ \\
\hline Age -65 & $\begin{array}{c}0.0012 \\
(0.65)\end{array}$ & $\begin{array}{l}0.0027 * * * \\
(3.72)\end{array}$ & $\begin{array}{l}0.0009 * * * \\
\quad(3.24)\end{array}$ & $\begin{array}{l}0.0005^{* *} \\
(2.04)\end{array}$ \\
\hline Constant & $\begin{array}{l}0.4942 * * * \\
\quad(4.75)\end{array}$ & & & \\
\hline Pseudo $R^{2}$ & & 0.0652 & 0.0639 & 0.0710 \\
\hline Sample size $n$ & $\begin{array}{c}14,751 \\
0.1033^{* * *}\end{array}$ & $\begin{array}{c}14,747 \\
0.0695^{* * *}\end{array}$ & $\begin{array}{c}14,738 \\
0.0671 * * *\end{array}$ & $\begin{array}{c}14,740 \\
0.1572 * * *\end{array}$ \\
\hline$\frac{\partial L 2}{\partial D}=\alpha_{D} / \alpha_{L 2}$ & & & & \\
\hline$\frac{\partial L 3}{\partial D}=\alpha_{D} / \alpha_{L 3}$ & $0.1200^{* * *}$ & $0.0965^{* *}$ & $0.0528 * *$ & $0.1180 * * *$ \\
\hline$\frac{\partial L 4}{\partial D}=\alpha_{D} / \alpha_{L 4}$ & $0.1920^{*}$ & 0.1511 & $0.0496^{*}$ & $0.1985^{* * *}$ \\
\hline
\end{tabular}

${ }^{a}$ Significance levels on coefficients: $* 10 \%$; **5\%; ***1\%. Cluster SEs for all coefficients based on the AD Center involved. Probit coefficients are the marginal effects.

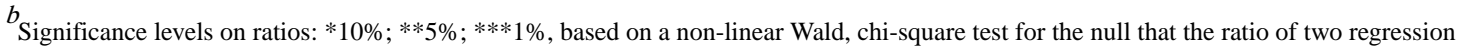
coefficients equals zero. $z$-Scores in parentheses. 
Table 4

RD analysis of Medicare on dementia using OLS ${ }^{a}$.

\begin{tabular}{lcc}
\hline Variable & Basic RD model & Varying slopes RD model \\
\hline Medicare $M: \beta_{1}$ & $-1.3173^{* * *}$ & $-0.9182^{* * *}$ \\
& $(5.31)$ & $(4.44)$ \\
Age - 65): $\beta_{2}$ & $0.1226^{* * *}$ & $0.0378^{* * *}$ \\
& $(8.11)$ & $(3.20)$ \\
(Age - 65) $\times$ M: $\beta_{3}$ & & $0.1079^{* * *}$ \\
& & $(4.41)$ \\
Male & $0.3423^{* * *}$ & $0.3316^{* * *}$ \\
& $(2.64)$ & $(2.60)$ \\
Log education & $-3.2048^{* * *}$ & $-3.14017^{* * *}$ \\
& $(9.95)$ & $(9.80)$ \\
APOE (one copy) & $1.8698^{* * *}$ & $1.8861^{* * *}$ \\
& $(13.99)$ & $(14.13)$ \\
APOE (two copies) & $3.3612^{* * *}$ & $3.4314^{* * * *}$ \\
& $(18.14)$ & $(19.29)$ \\
Sibling & $0.3619^{* * *}$ & $0.3284^{* * *}$ \\
& $(4.07)$ & $(3.72)$ \\
Height & $0.0510^{* * *}$ & $0.0498^{* * *}$ \\
& $(3.88)$ & $(3.81)$ \\
Constant & $7.1161^{* * *}$ & $6.3712^{* * *}$ \\
Pseudo $R^{2}$ & $(5.67)$ & $(5.15)$ \\
Sample size $n$ & 0.1932 & 0.1985 \\
\hline & 11,568 & 11,568 \\
\hline
\end{tabular}

${ }^{a}$ Significance levels on coefficients: $* 10 \%$; **5\%; $* * * 1 \%$. Cluster SEs for all coefficients based on the AD Center involved. $t$-Statistics in parentheses. 


\section{Table 5}

Estimate of the benefits for the three components by independent living level using GDS.

\begin{tabular}{|c|c|c|c|c|}
\hline & Component 1 & Component 2 & Component 3 & Benefits \\
\hline \multicolumn{5}{|c|}{ Medicare benefits at the year of eligibility } \\
\hline Benefits for $L 2$ & $\$ 13,188$ & 0.1033 & 0.9182 & $\$ 1251$ \\
\hline Benefits for $L 3$ & $\$ 27,789$ & 0.1200 & 0.9182 & $\$ 3062$ \\
\hline Benefits for $L 4$ & $\$ 28,501$ & 0.1920 & 0.9182 & $\$ 5025$ \\
\hline Total benefits & & & & $\$ 9338$ \\
\hline \multicolumn{5}{|c|}{ Medicare benefits at 7.28 years after eligibility } \\
\hline Benefits for $L 2$ & $\$ 13,188$ & 0.1033 & 0.1327 & $\$ 181$ \\
\hline Benefits for $L 3$ & $\$ 27,789$ & 0.1200 & 0.1327 & $\$ 443$ \\
\hline Benefits for $L 4$ & $\$ 28,501$ & 0.1920 & 0.1327 & $\$ 726$ \\
\hline Total benefits & & & & $\$ 1350$ \\
\hline
\end{tabular}




\section{Table 6}

Medicare benefits at the year of eligibility by independent living level using GDS2, GDS12, GDS15 and the production function to estimate component 2.

\begin{tabular}{|c|c|c|c|c|}
\hline & Component 1 & Component 2 & Component 3 & Benefits \\
\hline \multicolumn{5}{|c|}{ GDS2 for component 2} \\
\hline Benefits for $L 2$ & $\$ 13,188$ & 0.0695 & 0.9182 & $\$ 842$ \\
\hline Benefits for $L 3$ & $\$ 27,789$ & 0.0965 & 0.9182 & $\$ 2462$ \\
\hline Benefits for $L 4$ & $\$ 28,501$ & 0.1511 & 0.9182 & $\$ 3954$ \\
\hline Total benefits & & & & $\$ 7258$ \\
\hline \multicolumn{5}{|c|}{ GDS12 for component 2} \\
\hline Benefits for $L 2$ & $\$ 13,188$ & 0.0671 & 0.9182 & $\$ 813$ \\
\hline Benefits for $L 3$ & $\$ 27,789$ & 0.0528 & 0.9182 & $\$ 1347$ \\
\hline Benefits for $L 4$ & $\$ 28,501$ & 0.0496 & 0.9182 & $\$ 1298$ \\
\hline Total benefits & & & & $\$ 3458$ \\
\hline \multicolumn{5}{|c|}{ GDS15 for component 2} \\
\hline Benefits for $L 2$ & $\$ 13,188$ & 0.1572 & 0.9182 & $\$ 1904$ \\
\hline Benefits for $L 3$ & $\$ 27,789$ & 0.1180 & 0.9182 & $\$ 3011$ \\
\hline Benefits for $L 4$ & $\$ 28,501$ & 0.1985 & 0.9182 & $\$ 5195$ \\
\hline Total benefits & & & & $\$ 10,109$ \\
\hline \multicolumn{5}{|c|}{ Production function for component 2} \\
\hline Benefits for $L 2$ & $\$ 13,188$ & 0.0278 & 0.9182 & $\$ 337$ \\
\hline Benefits for $L 3$ & $\$ 27,789$ & 0.0199 & 0.9182 & $\$ 508$ \\
\hline Benefits for $L 4$ & $\$ 28,501$ & 0.0064 & 0.9182 & $\$ 167$ \\
\hline Total benefits & & & & $\$ 1012$ \\
\hline
\end{tabular}

Appl Econ. Author manuscript; available in PMC 2018 October 19. 